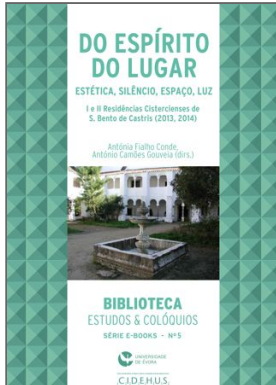

Antónia Fialho Conde and António Camões Gouveia (dir.)

Do Espírito do Lugar - Música, Estética, Silêncio, Espaço, Luz

I e II Residências Cistercienses de São Bento de Cástris (2013, 2014)

Levantamento de danos dos azulejos da Capela de Nossa Senhora do Rosário do Mosteiro de São Bento de Cástris

\author{
Marta Tamagnini Mendes, Teresa Ferreira, Sílvia Pereira and António \\ Candeias
}

Publisher: Publicações do Cidehus

Place of publication: Évora

Year of publication: 2016

Published on OpenEdition Books: 13

septembre 2016

Serie: Biblioteca - Estudos \& Colóquios

\title{
Q books
}

http://books.openedition.org

\section{Electronic reference}

MENDES, Marta Tamagnini ; et al. Levantamento de danos dos azulejos da Capela de Nossa Senhora do Rosário do Mosteiro de São Bento de Cástris In: Do Espírito do Lugar - Música, Estética, Silêncio, Espaço, Luz: I e /l Residências Cistercienses de São Bento de Cástris $(2013,2014)$ [online]. Évora: Publicações do Cidehus, 2016 (generated 27 October 2016). Available on the Internet: <http://books.openedition.org/ cidehus/2101>. ISBN: 9782821875029. DOI: 10.4000/books.cidehus.2101. 
Levantamento de danos dos azulejos da Capela de Nossa Senhora do Rosário do Mosteiro de São Bento de Cástris

\section{T. Mendes, T. Ferreira, S. Pereira, A. Candeias*}

\section{Abstract}

The Chapel of Nossa Senhora do Rosário is located in the cloister of the São Bento de Cástris monastery and shows off a blue and white tile panel with 6 tiles of height, representing the scenes of the Life of the Virgin in five panels: Adoration of the Shepherds, Presentation of the Virgin in the Temple, Annunciation, Visitation and The Marriage of the Virgin. The authorship of this work is unknown and its date has not yet found consensus.

The tiles are in poor condition and have been the target of repeated vandalism or attempted theft over time.

During the Residência Cisterciense (Cistercian Residence), held in São Bento de Cástris in September 2013, it has been made a survey of the tile panel's observable damages including graphic and photographic record of its condition.

Keywords: azulejo, conservation, damage, record, S. Bento de Cástris

\section{Resumo}

A Capela de Nossa Senhora do Rosário situa-se no claustro do mosteiro de São Bento de Cástris em Évora e ostenta um silhar baixo, de 6 azulejos de altura, representando a azul e branco cenas da Vida da Virgem em cinco painéis: Adoração dos Pastores, Apresentação da Virgem ao Templo, Anunciação, Esponsórios e Visitação. A data desta obra é incerta e a autoria permanece desconhecida.

Os azulejos encontram-se em mau estado de conservação e têm sido alvo de sucessivas tentativas de furto e vandalismo, ao longo dos tempos, com particular incidência após o ano de 2005, altura em que a secção masculina da Casa Pia de Évora desocupou este edificado.

No âmbito da Residência Cisterciense, que decorreu em São Bento de Cástris em Setembro de 2013, foi realizado um levantamento dos danos observáveis nestes painéis de azulejos bem como o seu registo gráfico e fotográfico.

\footnotetext{
* Marta Tamagnini Mendes (UÉ, HERCULES, LNEC/DM-NBPC), Teresa Ferreira (UÉ, HERCULES), Sílvia Pereira (LNEC/DM-NBPC), António Candeias (UÉ. HERCULES, Lab. José de Figueiredo)

Marta Tamagnini Mendes é conservadora na área da azulejaria enquanto Teresa Ferreira, Sílvia Pereira e António Candeias são químicos a desenvolver trabalho na área do Património. Em conjunto, têm-se debruçado sobre várias questões relacionadas com o azulejo, nomeadamente, materiais e processos de produção, patologias, padrões de degradação e evolução de intervenções de conservação e restauro.
} 
Palavras-chave: azulejo, conservação, danos, registo, S. Bento de Cástris

Introdução

A Capela de Nossa Senhora do Rosário situa-se no piso inferior do claustro do mosteiro de São Bento de Cástris. Nesta pequena capela de planta rectangular encontra-se um silhar baixo com 6 azulejos de altura. O conjunto de cinco painéis representa, a azul e branco, cenas da Vida da Virgem: Adoração dos Pastores, Apresentação da Virgem ao Templo, Anunciação, Esponsórios e Visitação ${ }^{1}$. A autoria desta obra não é conhecida e a sua datação ainda não encontrou consenso, sendo atribuída ao segundo quartel do século XVIII (c.1745) ${ }^{2}$ e, simultaneamente, reconhecida como produção de cerca de 1765-68 ${ }^{1}$.

\section{Factores de degradação}

Sendo o azulejo património integrado, o levantamento de danos deve passar pelo diagnóstico dos painéis em si, bem como da estrutura arquitectónica que os sustenta (naquilo que interfere directamente com o conjunto azulejar), assim como do meio em que se insere.

São factores de degradação dos revestimentos azulejares: a utilização de materiais e/ou técnicas inadequados; alterações na resistência estrutural do suporte arquitectónico; a acção dos agentes atmosféricos; o envelhecimento natural; e os actos de vandalismo ou incúria.

A resistência estrutural do suporte arquitectónico deve ser avaliada, verificando-se a existência de fendas a nível estrutural, bem como a eventual perda de função das argamassas, no geral e, em particular das argamassas de assentamento, com consequente perda de aderência dos azulejos.

As fracturas, fissuras e destacamentos de vidrados são danos, por vezes, designados como sendo de carácter estético mas reflectem muitas vezes problemas ao nível do suporte arquitectónico e das argamassas, assim como a presença de sais, a infestação por microorganismos ou mesmo o desenvolvimento de plantas superiores.

A água é um dos factores de degradação mais nefasto e encontra-se normalmente presente na forma de humidade em qualquer edifício. No seu interior, as oscilações diárias dos valores de humidade relativa em conjunto com as variações da temperatura, provocam períodos de condensação de água e consequentes escorrências pelos vidrados. No

\footnotetext{
${ }^{1}$ SIMÕES, J. M. dos Santos, Azulejaria em Portugal no Século XVIII. Lisboa: Fundação Calouste Gulbenkian, 2010 (2 ${ }^{\mathrm{a}}$ edição).

${ }^{2}$ VERÃO, Teresa, Os azulejos do Mosteiro de São Bento de Cástris de Évora, In CENÁCULO Boletim on line do Museu de Évora, n. ${ }^{\circ}$ 4, Outubro 2010, pp.3-14
} 
exterior, para além da condensação de água, também a água da chuva escorre pelas superfícies vidradas aumentando os efeitos de degradação causados pela sua acção.

A presença de sais é mais uma consequência da acção da água, que ao ascender por capilaridade transporta consigo sais solúveis de diversas origens. Com as variações dos valores de humidade, estes cristalizam na superfície ou no interior do azulejo, dependendo de como se desenvolve o processo, promovendo o surgimento de danos irreversíveis.

Ambientes húmidos são ambientes perfeitos para o desenvolvimento de microorganismos, como algas, fungos, líquenes e musgos, entre outros. Os processos de deterioração associados a este tipo de agentes podem levar à metabolização de alguns compostos inorgânicos, conduzindo à falta de coesão dos materiais cerâmicos. Os fungos produzem manchas e erosão e os líquenes e os musgos causam degradação mecânica. ${ }^{3}$

A poluição é um factor inerente à nossa atmosfera sendo no entanto mais frequente em meios urbanos, através da libertação de diversos contaminantes atmosféricos provenientes da circulação automóvel e/ou da indústria, que contribuem para a degradação do azulejo na medida em que se vão concentrando na sua superfície sob a forma de poeiras e manchas.

Por último, os actos de vandalismo e incúria, de carácter intencional ou não, podem contribuir para a sua alienação e descaracterização, por exemplo, através do furto consumado ou da sua tentativa.

A consequência destes factores é normalmente visível e consubstanciada nos diversos danos presentes em azulejos, como sejam: sujidades superficiais e manchas, destacamento de vidrados, fracturas e fissuras, lacunas, azulejos em risco de queda, perda de função das argamassas de assentamento, azulejos em falta.

\section{Os painéis da Capela de Nossa Senhora do Rosário - Estado de Conservação}

O revestimento azulejar da Capela de Nossa Senhora do Rosário é composto por cinco painéis com cerca de 392 azulejos de $14 \mathrm{~cm}$ x14 cm e com cerca de $1 \mathrm{~cm}$ de espessura.

Relativamente ao estado de conservação dos painéis, encontram-se 11 azulejos fracturados (Fig. 1), 8 trocados, 35 com lacunas e mais de $150 \mathrm{com}$ destacamento de vidrados (Fig. 2). Verifica-se, também, 7 azulejos em falta e foram encontrados quatro fragmentos de azulejos no local (Figs. 3 e 4). O registo gráfico de danos dos 5 painéis encontra-se nas figuras 5 a 9.

${ }^{3}$ MORALES, A.F. 2007. La Cerámica Arquitectónica: Su conservación y restauración. Sevilla: Universidad de Sevilla, pp. 47 
Antónia Fialho Conde, António Camões Gouveia Do Espírito do Lugar - Música, Estética, Silêncio, Espaço, Luz

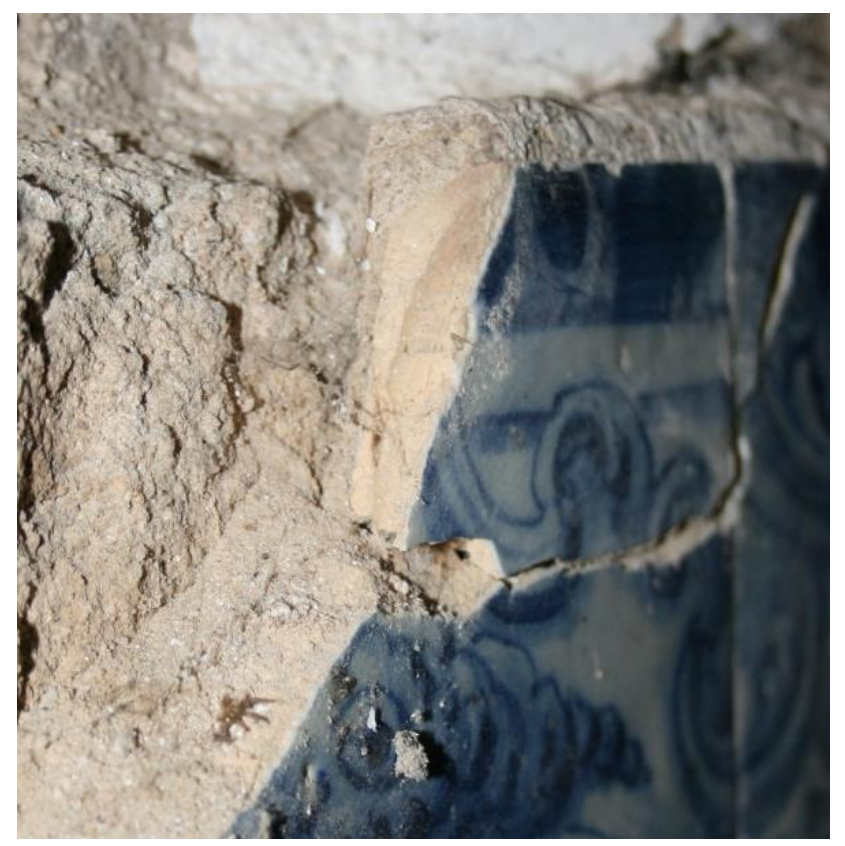

Figura 1. Pormenor de azulejo fracturado no painel Adoração dos Pastores.

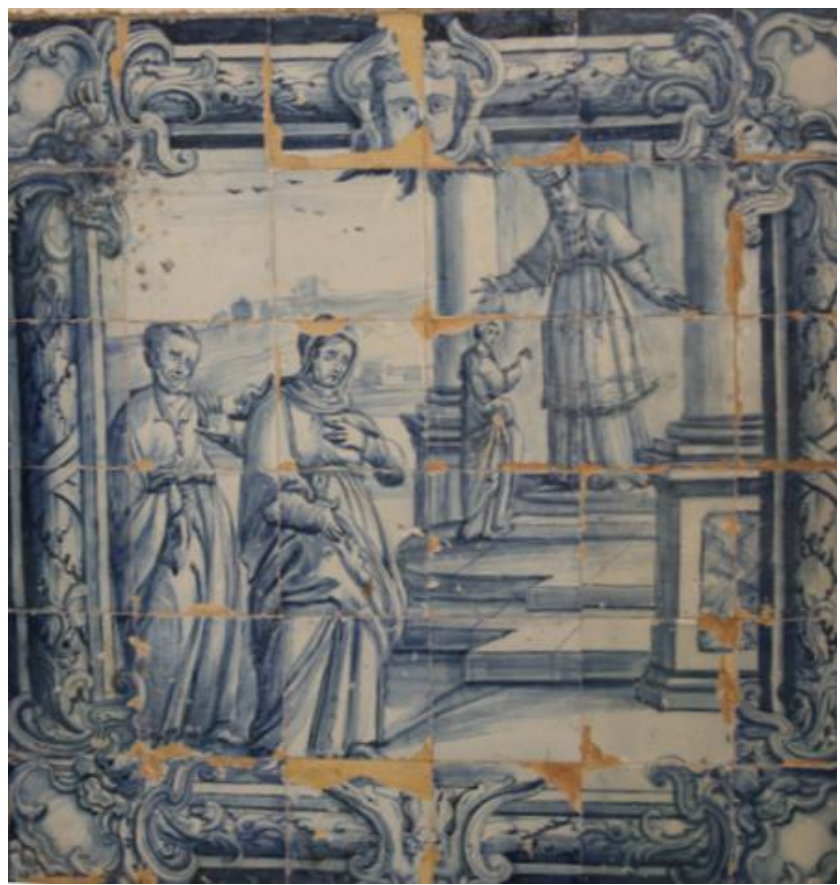

Figura 2. Destacamento de vidrados no painel Apresentação da Virgem ao Templo. 
Observou-se a presença de humidade junto ao altar e verificou-se a existência de sujidades superficiais e concrecionadas (argamassas, tintas, ceras, entre outras) sobre os vidrados e o seu destacamento devido à acção de sais solúveis. As argamassas de assentamento permanecem estáveis e cumprindo a sua função. Por este motivo considerase que os azulejos em falta terão sido alvo de furto, devido ao facto de se encontrarem em zonas de mais fácil acesso, ou seja, no limite do painel, e pelo tipo de danos provocados nos azulejos adjacentes, decorrentes do seu levantamento, com formação típica de fracturas e de lacunas, devidas às ferramentas utilizadas e à dureza das argamassas de assentamento.
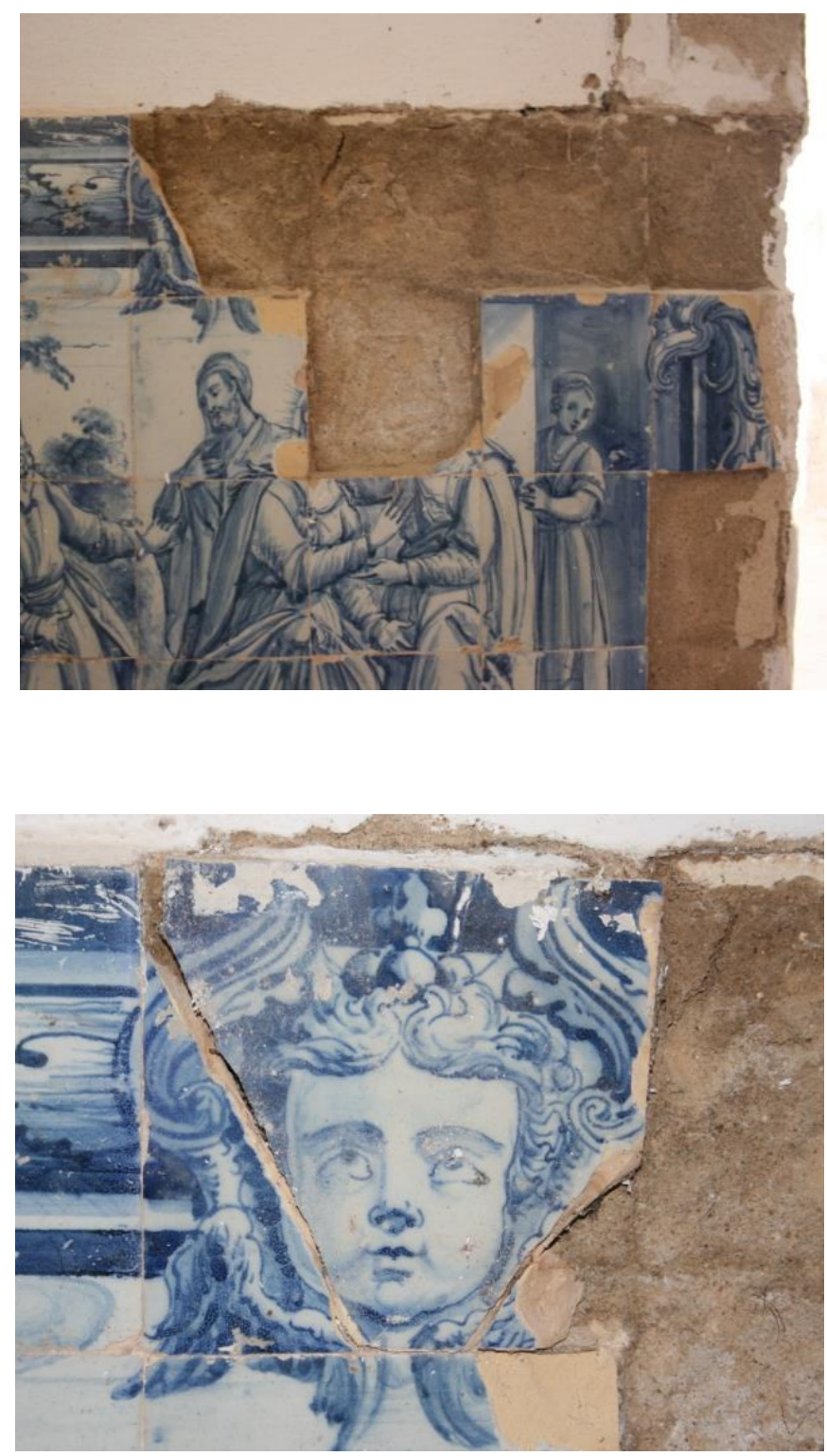

Figura 3 e 4. Painel Visitação- Pormenor dos azulejos em falta e de um dos fragmentos que se encontra no local 


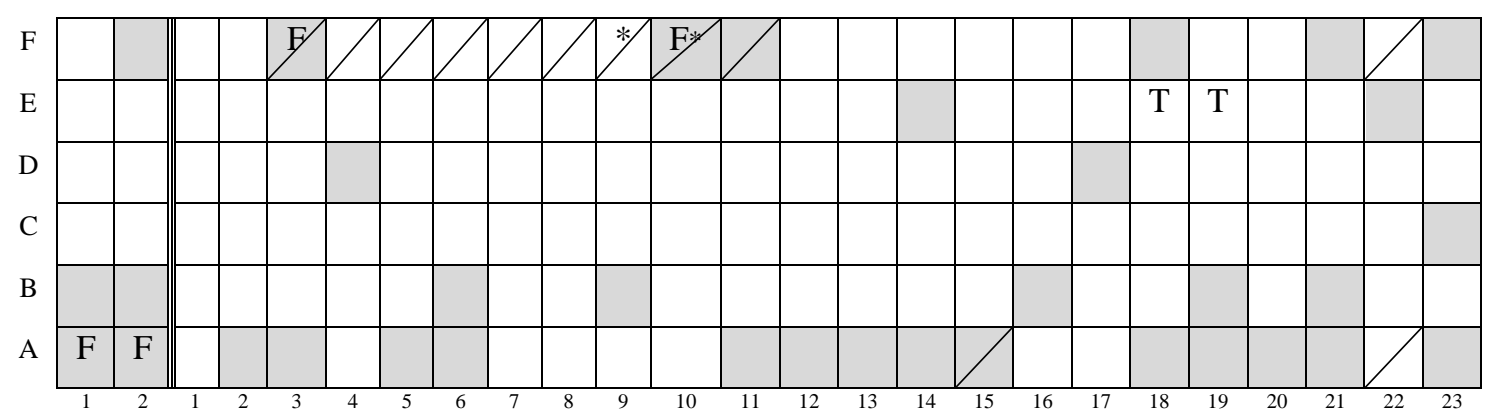

Figura 5. Adoração dos Pastores

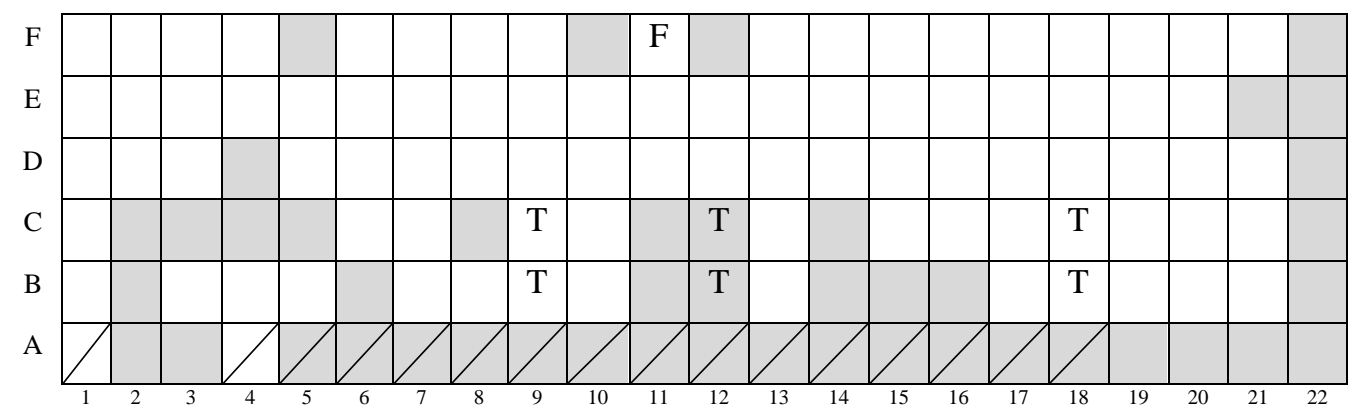

Figura 6. Esponsórios

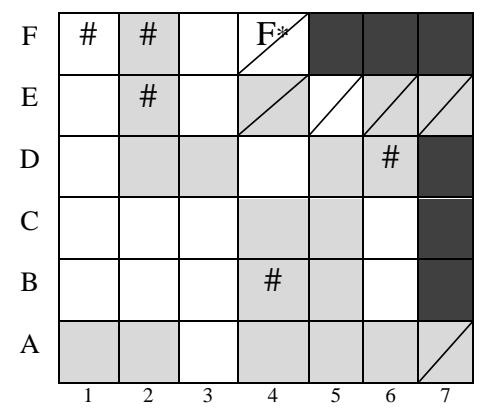

Figura 7. Visitação 

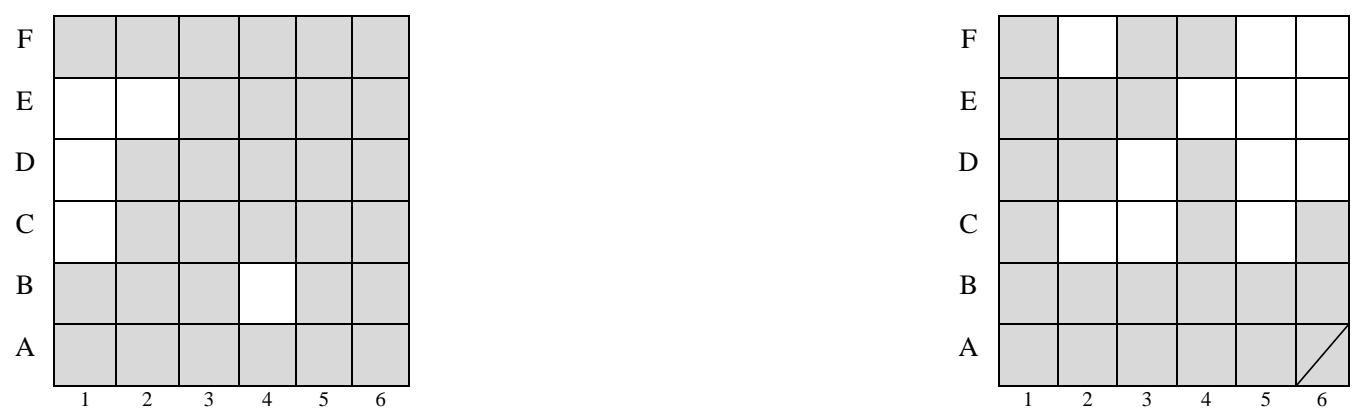

Figuras 8 e 9. Apresentação da Virgem ao Templo e Anunciação

\begin{tabular}{|c|c|c|c|c|c|}
\hline & Destacamento de vidrado & $\#$ & Fissura & $\mathrm{F}$ & Fractura \\
\hline Lacuna & $\mathrm{T}$ & Trocado/não pertence ao painel & & Em falta \\
\hline & $*$ Fragmentos/ parte dos fragmentos encontram-se no local \\
\hline
\end{tabular}

\section{Considerações finais}

Os painéis de azulejo da Capela de Nossa Senhora do Rosário do Mosteiro de São Bento de Cástris foram, muito provavelmente, encomendados para o local em causa devido ao cuidado visível no enquadramento das cenas e das molduras, adequando-se perfeitamente ao espaço arquitectónico. Representam, também por isso, um pequeno mas notável conjunto da azulejaria portuguesa do século XVIII.

Seria importante proceder à urgente inventariação de todo o património integrado que ainda se encontra no mosteiro, bem como ao levantamento do estado de conservação e seu registo, contribuindo assim para minimizar os efeitos de uma constante delapidação e desmembramento deste património, como vem acontecendo em numerosos edifícios.

A aplicação de medidas de conservação preventiva seria igualmente premente devido ao avançado estado de degradação deste conjunto, bem como a limitação do acesso ao edifício, fora das ocasiões em que se encontra aberto, pois por se situar em local ermo torna-se um alvo fácil de actos de furto e vandalismo. 